\title{
Response to the article "Perioperative standards for the treatment of coagulation disorders and usage of blood products in patients undergoing liver transplantation used in the Clinic for Transplant Surgery in Wrocław"
}

\author{
Jan Pluta ${ }^{\mathrm{D}-\mathrm{F}}$, Agnieszka Cieniewicz ${ }^{\mathrm{D} F}$, Janusz Trzebicki ${ }^{\mathrm{D}-\mathrm{F}}$ \\ Department of Anesthesiology and Intensive Care, Medical University of Warsaw, Poland \\ A - research concept and design; $\mathrm{B}$ - collection and/or assembly of data; $\mathrm{C}$ - data analysis and interpretation; \\ $\mathrm{D}$ - writing the article; $\mathrm{E}$ - critical revision of the article; $\mathrm{F}$ - final approval of the article
}

Address for correspondence

Jan Pluta

E-mail: jan.pluta@lekarz.eu

Funding sources

None declared

Conflict of interest

None declared

Received on September 24, 2018

Accepted on February 18, 2019

Published online on March 12, 2019

Cite as

Pluta J, Cieniewicz A, Trzebicki J. Response to the article "Perioperative standards for the treatment of coagulation disorders and usage of blood products in patients undergoing liver transplantation used in the Clinic for Transplant Surgery in Wrocław". Adv Clin Exp Med. 2019;28(3):415-416. doi:10.17219/acem/104539

DOI

10.17219/acem/104539

Copyright

Copyright by Author(s)

This is an article distributed under the terms of the

Creative Commons Attribution Non-Commercial License

(http://creativecommons.org/licenses/by-nc-nd/4.0/)

\begin{abstract}
We read with interest the article by Łukaszewski et al. published in Advances in Clinical and Experimental Medicine (Adv Clin Exp Med. 2018;27(9):1211-1215, published online on July 18 ${ }^{\text {th }}$, 2018, as ahead of print). As enthusiasts of promoting global assays of hemostasis, we would like to commend the authors for their commitment and effort in their implementation and clinical application. As the authors rightly pointed out in the article, perioperative care of liver transplantation (OLTx) patients is challenging for transplant team members due to the risk of severe changes in global hemostasis. Łukaszewski et al. presented a single center experience in using rotational thromboelastometry (ROTEM) to monitor hemostasis during liver transplantation. In our center, this method has been used routinely since 2008. So far it has been used in over 400 patients undergoing OLTX. Considering the potential contribution to thrombotic complications (including portal vein thrombosis after liver transplantation), we believe that antifibrinolytic treatment should be reserved for patients with active bleeding and hyperfibrinolysis confirmed by ROTEM. The available literature indicates an increased risk of thrombotic complications in patients receiving antifibrinolytic therapy. This raises an important question for the authors about the reason for using Exacy $\left.\right|^{\circledR}$ in all 12 of the cases presented, even in patients who did not require any blood product transfusion. We hope that our letter will open up further discussion on this subject, which is undoubtedly crucial for OLTx patients' safety.
\end{abstract}

Key words: hemostasis, liver transplantation, thromboelastometry, hyperfibrinolysis, tranexamic acid 
Response to the Article "Perioperative standards for the treatment of coagulation disorders and usage of blood products in patients undergoing liver transplantation used in the Clinic for Transplant Surgery in Wrocław"

We read with interest the article "Treatment of Coagulation Disorders" by Łukaszewski et al. published in Advances in Clinical and Experimental Medicine ( $A d v$ Clin Exp Med. 2018;27(9):1211-1215, as ahead of print on July $\left.18^{\text {th }}, 2018\right)$. As enthusiasts of promoting global assays of hemostasis, we would like to commend the authors for their commitment and effort in their implementation and clinical application.

As the authors rightly pointed out in the article, perioperative care of liver transplantation (OLTx) patients is challenging for transplant team members due to the risk of severe changes in global hemostasis. Liver failure leads to specific disorders in the coagulation and fibrinolysis system, referred to by Lisman et al. as "rebalanced hemostasis". ${ }^{1}$ Hemostasis assessment in OLTx patients is extremely difficult - often impossible when using only routine coagulation screening tests. Global assays of hemostasis such as rotary thromboelastometry (ROTEM) or thromboelastography (TEG) allow better understanding of existing coagulation abnormalities, which facilitates appropriate hemostatic management.

In their article Łukaszewski et al. presented a single center experience in using ROTEM to monitor hemostasis during liver transplantation. In our center, this method has been used routinely since $2008 .^{2}$ So far it has been used in over 400 patients undergoing OLTx. We fully agree with Łukaszewski et al. regarding the benefits of implementing this method. It allows early recognition of hyperfibrinolysis, which is undetectable using classical laboratory coagulation tests. Treatment, if necessary, includes administration of antifibrinolytics, currently tranexamic acid $\left(\right.$ Exacyl $\left.^{\circledR}\right)$.

Łukaszewski et al. stated that they introduced antifibrinolytic treatment when the maximum clot lysis (ML) in the EXTEM test was above 15\%. An important issue during ML evaluation is the time when lysis occurred (the time elapsed from the beginning to the end of measurement): it has to be specified. The Essen Algorithm, mentioned by Łukaszewski et al., includes the clot lysis index after $60 \mathrm{~min}$ (CLI60); administration of antifibrinolytics should be considered at values below $85 \%{ }^{2,3}$ The clot lysis index describes the percentage of maximum clot firmness (MCF) in relation to the $\mathrm{ML}$ value in a particular minute of the test. Maximum clot lysis values over $15 \%$ may be regarded as physiological if the test duration is significantly longer than $60 \mathrm{~min}$.
Additionally, we want to highlight that the occurrence of hyperfibrinolysis in liver cirrhosis patients during OLTx, especially late hyperfibrinolysis (over 30 min of ROTEM measurement) after reperfusion, is a self-limiting process that does not require antifibrinolytic therapy. ${ }^{3}$ Inhibition of fibrinolysis is recommended only in cases of clinical manifestations of coagulopathy.

In their results section, the authors stated that all the patients with confirmed hypofibrinogenemia received fibrinogen concentrate and Exacyl ${ }^{\circledR}$. We share their opinion that fibrinogen concentrate is the safest fibrinogen substitute in cases of confirmed hypofibrinogenemia. However, our concerns were raised about the prophylactic administration of Exacyl ${ }^{\circledR}$ described in the article. According to the previously mentioned Essen Algorithm, routine administration of tranexamic acid is suggested only for patients with hepatitis fulminans with no history of thrombosis, or patients with MCF $(\mathrm{EX}) \leq 35 \mathrm{~mm}$ or CT $(\mathrm{EX})>80 \mathrm{s.}^{4,5}$

Considering the potential contribution to thrombotic complications (including portal vein thrombosis after liver transplantation), we believe that antifibrinolytic treatment should be reserved for patients with active bleeding and hyperfibrinolysis confirmed with ROTEM. The available literature indicates an increased risk of thrombotic complications in patients receiving antifibrinolytic therapy. ${ }^{4,6}$ This raises an important question for the authors about the reason for using Exacyl ${ }^{\circledR}$ in all 12 of the cases presented, even in patients who did not require any blood product transfusion (Table 1, page 4).

We hope that our letter will open up further discussion on this subject, which is undoubtedly crucial for OLTx patients' safety.

\section{References}

1. Lisman T, Porte RJ. Rebalanced hemostasis in patients with liver disease: Evidence and clinical consequences. Blood. 2010;116(6):878-885.

2. Trzebicki J, Flakiewicz E, Kosieradzki M, et al. The use of thromboelastometry in the assessment of hemostasis during orthotopic liver transplantation reduces the demand for blood products. Ann Transplant. 2010;15(3):19-24.

3. Abuelkasem E, Lu S, Tanaka K, Planinsic R, Sakai T. Comparison between thrombelastography and thromboelastometry in hyperfibrinolysis detection during adult liver transplantation. Br J Anaesth. 2016;116(4):507-512.

4. Görlinger K. Coagulation management during liver transplantation [in German]. Hamostaseologie. 2006;26(3 Suppl 1):S64-S75.

5. Lier H, Vorweg M, Hanke A, Görlinger K. Thromboelastometry guided therapy of severe bleeding. Essener Runde algorithm. Hamostaseologie. 2013;33(1):51-61.

6. Ortmann E, Besser MW, Klein AA. Antifibrinolytic agents in current anaesthetic practice. Br J Anaesth. 2013;111(4):549-563. 